\title{
It Deepens Like a Coastal Shelf: Educational Mobility and Social Capital in Germany
}

\author{
Fabian Stephany ${ }^{1,2}$ (D)
}

Accepted: 28 May 2018 / Published online: 8 June 2018

(C) The Author(s) 2018

\begin{abstract}
The prospects for the next generation-whether young people, regardless of their backgrounds, have equal chances of social success-pose a momentous problem for modern societies. Inequality of opportunity, often reflected by social immobility, is a threat to the egalitarian promise and the stability of your society. This work argues that social capital transmission plays an important role for the chances of social success in Western societies. For the example of Germany, it is reasoned that weak social capital environments deepen existing disadvantages. Even though all levels of education are easily accessible and affordable, Germany has one of the lowest levels of educational mobility among the industrialized countries of the world. Problems appear to be systematic, since the decision regarding entry into higher secondary education is made at early age and is left, in most cases, with the parents, who rely on their own educational trajectory. Outside of the school environment, differences in social capital inheritance explain educational immobility. With the use of the German Socio-Economic Panel survey from 1984 to 2014, various analyses about the relation between social capital and educational success are performed. Social capital, which is helpful for educational and social success, clearly depends on the educational family background. This indirect link has been disregarded in past contributions. Alternative forms of schooling, such as comprehensive and all-day education, as well as a delay of the decision regarding entry into higher education, could help improving unequal social capital inheritance.
\end{abstract}

Keywords Educational inheritance $\cdot$ Two-stage least-squares $\cdot$ Ordered logistic regression $\cdot$ Social mobility $\cdot$ Social capital

JEL Classification $\quad \mathrm{I} 24 \cdot \mathrm{L} 14 \cdot \mathrm{Z} 13$

Fabian Stephany

fstephan@wu.ac.at

1 Wirtschaftsuniversitat Wien, Vienna, Austria

2 Wittgenstein Centre for Demography and Global Human Capital, Vienna, Austria 


\section{Introduction}

Inequality of wealth is an increasingly addressed theme in social science (Piketty 2015) and the impetus of several public debates and movements, such as the "We are the 99\%" initiative. The Inequality Matters 2013 report by the United Nations states that “ (...) growing inequality is responsible for all manner of political instability, as well as for the slowing of economic growth worldwide" (Lepore 2015). Several prominent scholars have agreed on this point, such as the economist Joseph Stiglitz in his book The Price of Inequality (Íşler 2015). The causes of inequality are much disputed.

\section{(...) Man hands on misery to man./ It deepens like a coastal shelf.}

Get out as early as you can,/ And don't have any kids yourself. Philip Larkin - This Be The Verse

Along the lines of Philip Larkins' cynical poem about inherited disadvantage, a growing body of literature suggests that equality of condition originates from equality of opportunity (Putnam 2015). While the first is concerned with the distribution of income, wealth, or living conditions, in general, the latter stems from the egalitarian goal that every person's chances of social success should be independent of ascribed characteristics such as sex, race, or class origin. If the egalitarian premise is undermined, by systematic reproduction and extension of existing stratification, segregation and political radicalisation begin to threaten the stability of democracy.

A widely used measure in social science research for equality of opportunity is social mobility. With the example of Germany, the outlined work argues that social mobility, in Western societies, is shaped by educational attainment and the transition of social capital. Social capital is unequally distributed across educational classes in the parents' generation and shows persistence in inheritance to the next generation. It has been pointed out that social capital and the abilities acquired through it are helpful for a successful educational development. A social capital stratification by educational background and a subsequent class-dependent inheritance explain similarities in the trajectories of subsequent generations and educational immobility.

The results of this work indicate that educational mobility in Germany in the last 10 years is still comparably low for the cohort of 25- to 35-year-olds. Particularly for obtaining higher secondary education or a university degree, the parental educational career is a strong predictor. Students with university-educated parents are almost three times as likely to gain a university degree themselves compared with children of parents without an academic background. In fact, the share of university graduates with academic parents has never been as high as today. While the population on average has become more educated, correlation in education between the generations has increased. As parental couples have become more homogeneous in terms of education over the last 30 years, the probability of growing up in a diverse educational environment has diminished. Descriptive findings on the relationship between parental education and social capital show that young adults from educationally more affluent backgrounds have stronger social capital. They have larger social networks, higher trust, and stronger social norms, compared with their counterparts from less-educated families. The two-stage least-squares (2SLS) model shows how parental social capital is first transmitted from one generation to the next and then, ultimately, shapes educational success. Social norms, such as lending money, for example, can be instrumented with parental social capital and are highly correlated with educational attainment. Past contributions have neglected this indirect connection, which 
explains a fair share of correlation between parental and child education in conventional models.

This work suggests that class-specific exposure to different social capital surroundings, inside and outside of schools, can explain the inheritance of social capital. Leisure time activities could be more beneficial for the development of social capital in well-educated families than in less-educated surroundings. In schools, the perpetual nature of social capital can lead to a similar effect. Social capital norms and trust are facilitated in a strong social capital environment, which is in return built by the individuals' level of social capital. The more segregated schools become, the more pronounced this effect will be. Regarding the channels of social capital transmission, in schools and in families, a more extensive all-day integrated comprehensive schooling and a later decision about entry into higher secondary education could potentially improve the degree of social capital inheritance and ease educational predetermination.

Additional research following this paper could be linked to the insight (Fauser et al. 2012) that a migrant family background, likewise to lower parental educational attainment, further diminishes the chances of obtaining a degree. Most migrant families are less accustomed to the specifics of the German educational system. At the same time, their social capital background might differ significantly from the original population. The GSOEP dataset provides a detailed sample of a relatively large migrant population in Germany for the year 2013. The understanding of educational equality for the migrant population becomes increasingly important in a culturally more diverse German society.

The proposed investigation proceeds in the following way; first, a description of the German school system, previous findings on the determinants of educational mobility, and the role of social capital are outlined, afterwards, the conceptual background of the analysis is outlined and research hypotheses are formulated, secondly, the use of the German Socio-Economic Panel (GSOEP) dataset and the applied empirical model are described. Individual educational attainment is explained by parental education, parental social capital and other socio-economic determinants. Since parental social capital jointly influences both a child's social capital and educational attainment, a 2SLS approach is implemented, in order to avoid distortions of the results due to endogeneity, thirdly, the results of the 2SLS model are interpreted and further possible determinants of educational mobility are discussed, the last section concludes.

\section{Literature Review and Research Hypotheses}

\subsection{The Case of Germany}

In education, Germany takes an exceptional role among the industrialised countries of the world, with regard to its low rates of tertiary degrees (OECD 2015, 39). A result from the 2014 OECD Education at a Glance comparative study depicted in Fig. 1 shows that Germany has one of the lowest ranks in terms of educational mobility within the member countries.

All pupils in Germany begin their educational career with the same first step, the entry into primary education. Therefore, a 'stock-like' analysis of the German educational system does not reveal where the separation between pupils takes place. The work by Hillmert and Jacob (2010) is one of the first investigations that applies a transitional view on the topic of German educational mobility and follows a cohort of pupils over time. Figure 2 sketches 


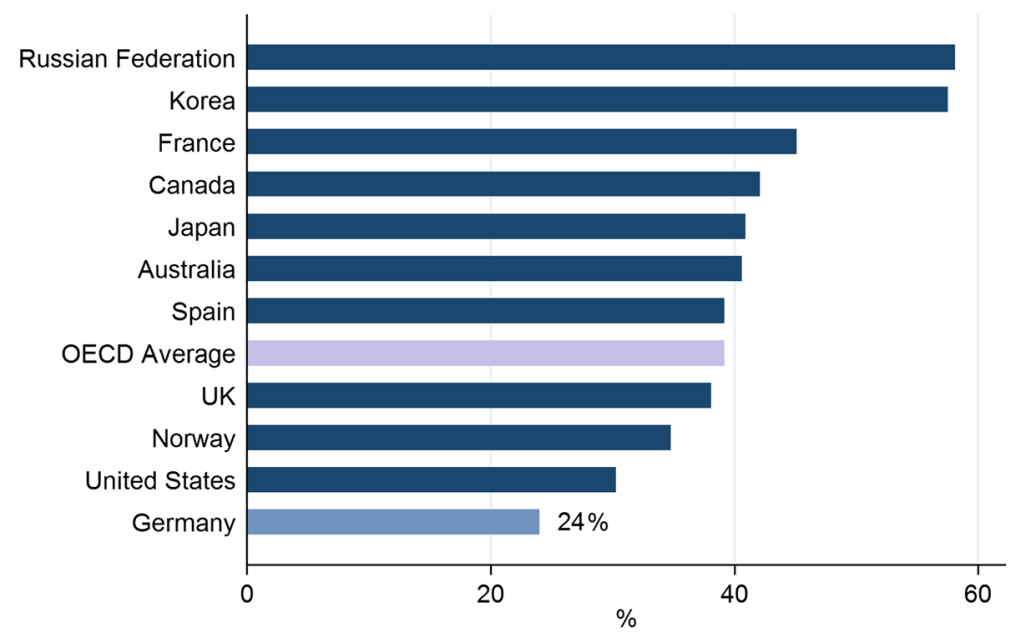

$\%$ of 25-64 year-olds whose educational attainment is higher than that of their parents Source: OECD Education at a Glance 2014

Fig. 1 In 2014, only $24 \%$ of the population obtains an education higher than their parents. Source: OECD 2014 Education at a Glance

the German school system in its current state. A very detailed description ${ }^{1}$ of the specifics of the German education system can be found in Hillmert and Jacob (2010). At the end of the educational career of the 1964 cohort, on average, a chance for children from academic households of obtaining a uni degree are more than six times higher than for children with parents who had themselves never been to university (Hillmert and Jacob 2010, 72).

Hillmert and Jacob (2010) show that educational attainment of Germany's 1964 'baby boomer' cohort is strongly related to their parents' education. The institutional settings, such as Germany's sound vocational training sector and the early decision making about a child's entry into higher secondary education, are key in this mechanism. This work relates to these previous findings and examines the 25- to 35-year-olds in 2003, 2008, and 2013, who were not in formal education at the moment of the survey interview. In the last 25 years, the demand-driven developments on the labour market and changes in the German schooling system, should have fostered transition into tertiary education and eased problematic intergenerational rigidities in educational attainment. ${ }^{2}$

\footnotetext{
${ }^{1}$ On average, of 100 children from highly-educated households 63 entered the Gymnasium directly, while only 21 children from low-educated households make this achievement. After some fluctuation within the secondary system, the numbers remain relatively stable: 64 pupils with higher-educated parents obtain the Abitur and 19 of low-educated origin. The numbers say that is was more than three times as likely for a child with academic household background to gain the university attendance certificate than for a child with less-educated parents. During the course of tertiary education the numbers, naturally, shrink on both sides, but the background cleavage widens at the same time. Of the 32 pupils from well-educated homes, who, on average, entered university, 31 obtained a degree. On the other side, only seven children with less-educated parents directly began to study at university and five finished their degree in the end.

${ }^{2}$ The increasing global demand for high skilled, university-educated labour and the growing educational opportunities abroad should have facilitated the interest for university degrees. Similarly, institutional changes should have created further interest in obtaining a tertiary degree. The introduction of the BA/MA $(3+2$ years) system, contrasts with the image of the university degree as a 5-year long-term investment. Likewise, Polytechnics, tertiary institutions with a strong practical and technical focus, have initiated, in cooperation with large companies, so-called extra occupational (berufsbegleitende) degrees, which allow
} 
Fig. 2 The German school system has a strong 'academic track' (arrows on the very left). Source: GSOEP 2015 and own calculations

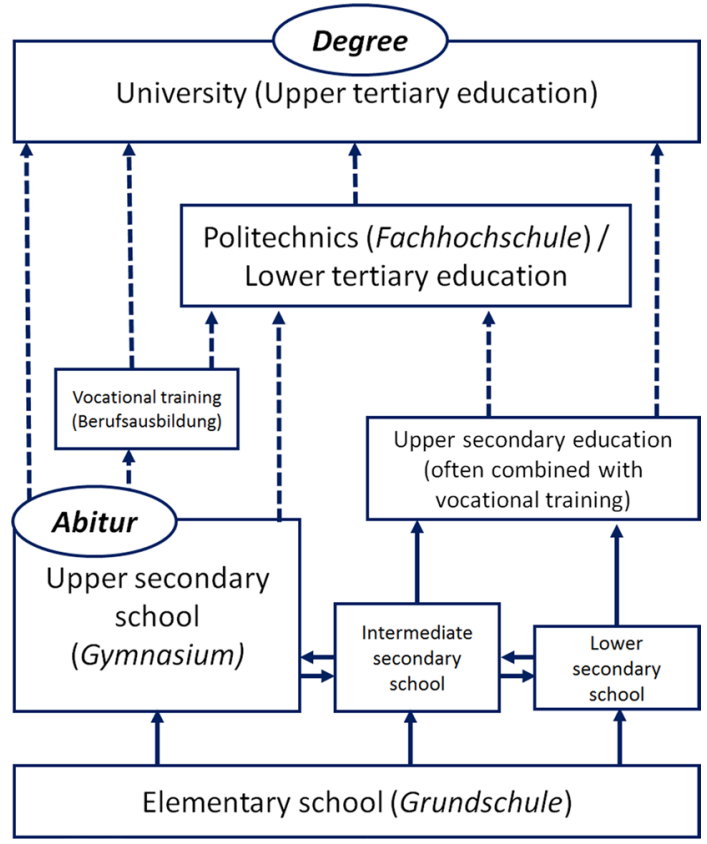

But even in the light of institutional changes and rising demand for university-educated labour force, mobility remains low in Germany. The theory of social capital inheritance bridges the conceptual gap in explaining educational mobility. As social capital plays an important role in childhood development, it can be assumed that class-specific social capital transmission is one cause of educational stratification. Again, the structure of the German education system plays an important role with regard to social capital transmission inside and outside of schools. At a relatively early age of about 10 years old, after the completion of elementary school, pupils are separated into lower, medium, and higher secondary education. This early and distinct separation into educational classes leads to segregated social capital environments. The perpetual facilitation of social capital is most likely to take place in schools with individuals of higher educational background. At the same time, school ends in most cases around midday. All-day schooling or school organised leisure activities are still exceptional. For the rest of the day, pupils are exposed to their private social surrounding, which allows family levels of social capital to consolidate.

\subsection{What Determines Educational Success}

Educational mobility is a widely investigated topic in social science research. In the face of the broad range of discussions about educational mobility in the literature, the following review of past contributions focuses on studies with conceptual aspects similar to the presented work. The papers on educational attainment discussed in the following paragraph

Footnote 2 (continued)

students to gain a certificate from a polytechnic university and make some first paid experiences on the labour market, at the same time. 
are empirical contributions using national panel data. Most papers approach the topic of educational mobility with a Logit/Probit Multi-Level Model. They mainly focus on Western Europe and North America. Two studies present a cross-national comparison. A summary of the nine most cited works is given in Tables 1 and 2.

The presented studies have diverse explanations for educational success. One approach is to find determinants of educational success in the institutional setting. The attendance of elite schools (Davies et al. 2014) or targeted policy interventions (Stadelmann-Steffen 2011) could be used to explain differences in educational success. Other researchers look for determinants in the way kids are raised. Media socialisation (Notten and Kraaykamp 2010) or the exposure to cultural capital (Tramonte and Willms 2010) show effects on educational outcomes. Likewise, the parental well-being can serve as an explanation. Bad parental health conditions (Roos et al. 2013) or parental imprisonment (Hagan and Foster 2012) are severe social distortions that can lead to academic failure.

To conclude, all studies underline the relevance of parental education for educational success. Across countries, parental education is the strongest determinant of educational success (Van Doorn et al. 2011). Personal characteristics, like migration background and health, are relevant for educational attainment, too. The socio-economic background of the parents and the mother's age at birth are likewise strong determinants of educational achievement. The presented work extents these confirmed influences with a set of social capital indicators.

\subsection{About Social Capital}

The concept of social capital has been characterised by many aspects in sociological literature, most prominent discussants of the definition, role, and empirical measurement of social capital are Bourdieu (1986), Coleman (2000), and Putnam (1995). Throughout the theoretical debate about social capital, three distinct facets have emerged: trust, norms, and networks (Coleman 2000). The three concepts of social capital are interlinked. Putnam et al. (1994) originally noted that networks, which provide access to resources of value cannot exist without social norms that control behaviour and encourage actors to engage in collective action for the benefit of the group. Social trust, similarly, is seen as an inclusive element of the three-dimensional social capital, since it limits exploitation and facilitates exchange in the group.

The ambiguous characterisation of social capital set the stage for criticising its empirical content (Solow 1995 in Knack and Keefer 1997, p. 1255). In order to deal with this critique, many different empirical measurements of social capital have been constructed. Of all these conceptualisations generalised trust (in other people in the society) has enjoyed most attention. Trust, in this respect, has been used to approximate social capital on an empirical basis. However, there are many contributions in social capital research that employ other indicators.

\subsection{Social Capital and Educational Success}

Several previous investigations have pointed towards a strong link between social capital and educational success. In a high social capital background, parental involvement in school activities (Putnam 1995) and discussions of school activities (Sandefur et al. 2006) are vitally linked to success in school. In addition, social networks can help to foster educational success. The tendency of joining social networks of members who are much like 


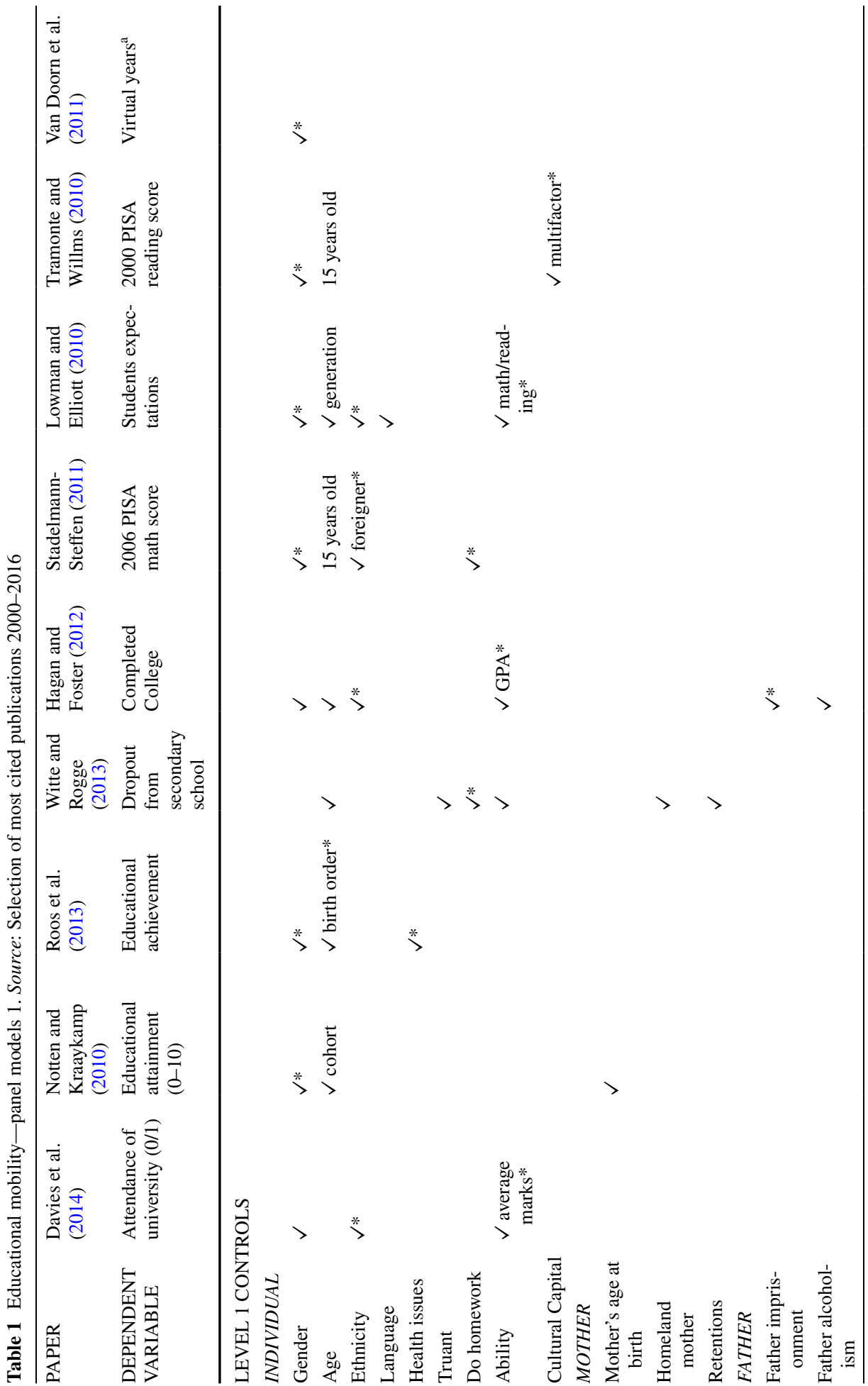




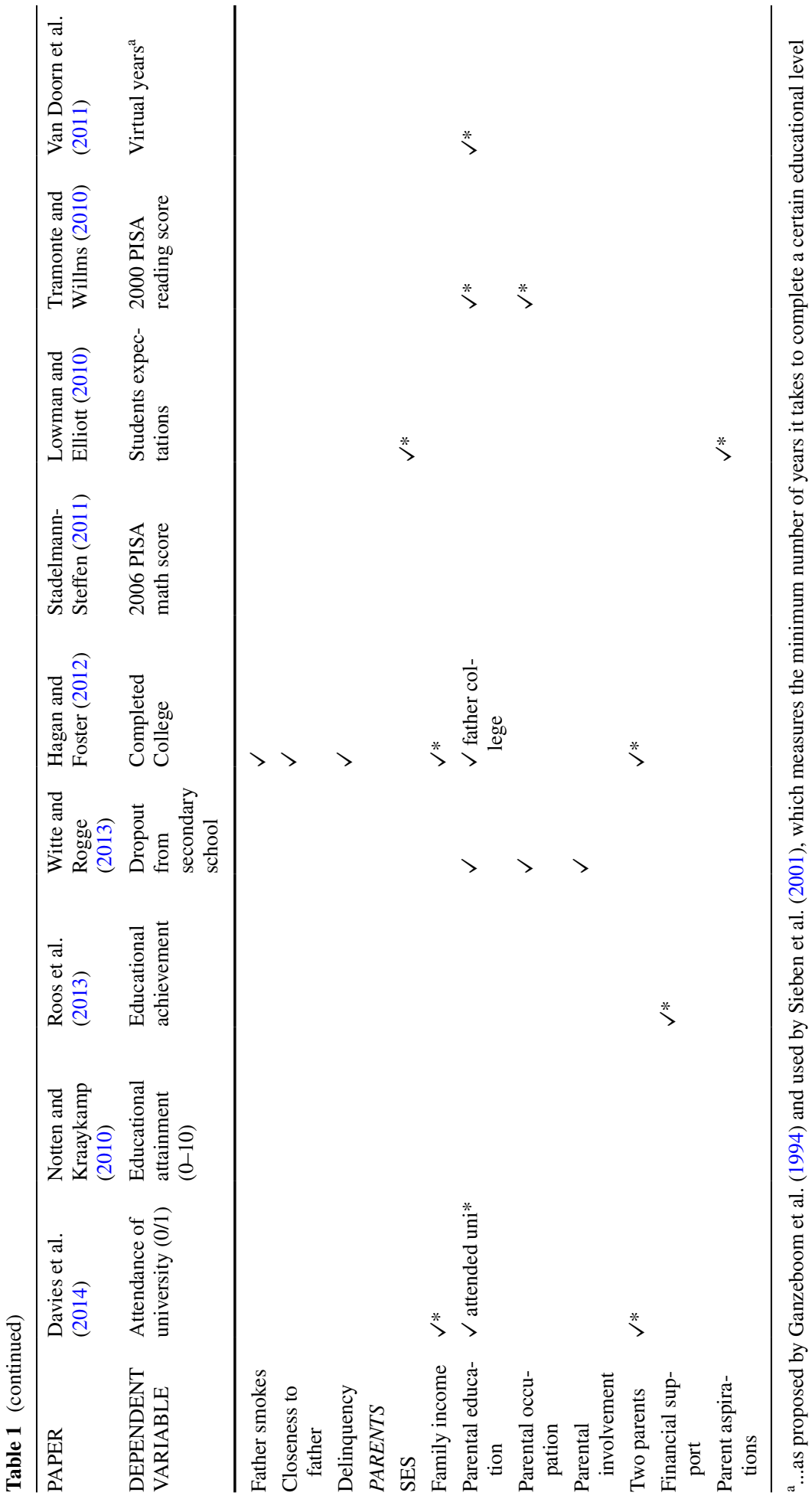




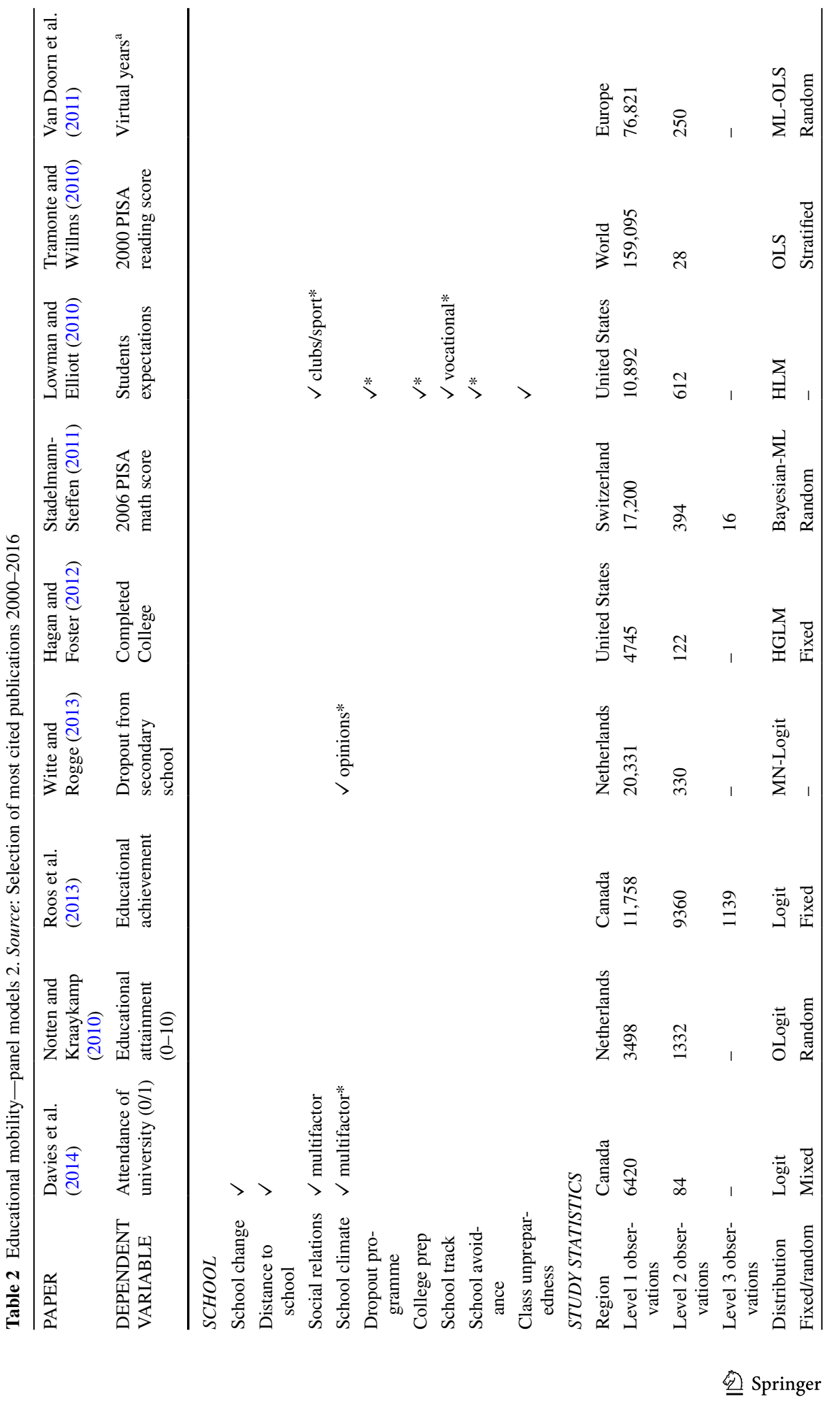




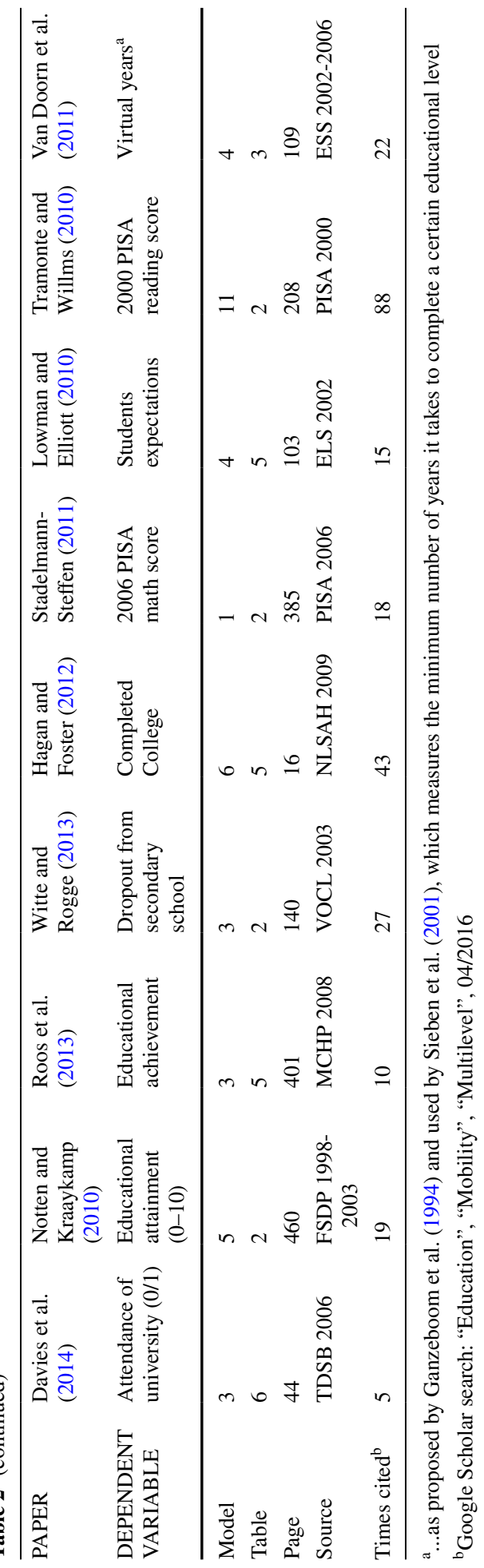




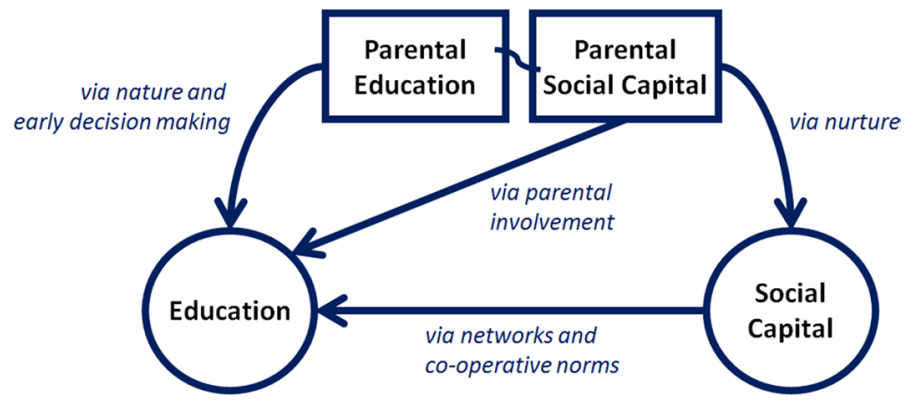

Fig. 3 Education and parental background are intricately correlated

one's self with respect to levels of social capital, creates an environment, which can be helpful but also destructive for an educational development (Lin 2000). In particular, for vocational secondary education, parental social capital is important (Jäger and Holm 2007). "Knowing the right people" and finding an apprenticeship position is potentially very influential, and parents with vocational professions are likely to help at this point.

Social capital and educational success are mainly linked in two ways: networks and skills. On the one hand, social capital, defined as network ties, allows individuals to pursue their goals with the help of others. The support of other individuals, parents, grandparents, friends, teachers, colleagues or mentors, is a determinant factor of success in educational careers. In the case of education, social networks can help children overcome social pressure or difficulties in academic tasks, such as homework or tests. On the other hand, the abilities and skills acquired in the surrounding of high social capital networks are helpful for educational achievement. Features like trust in others or self-reliance are often established in environments of high social capital. The interaction with others fosters the capability for teamwork, cooperative problem solving, and eases orientation in social structures and hierarchies.

Education and social capital potentially interact at several points in time. At an initial stage, educational success can be stimulated by social skills and networks, as described earlier. Similarly, certain types of schooling environments can foster social capital acquisition, such as enlarging one's social network or establishing trust. This mutual mechanism continues to operate during the whole life course, including periods of adult education, which are not considered in this work, due to the design of the research question.

\subsection{Research Hypotheses}

This work analyses the relationship between parental background and educational attainment of the child. It argues that an unequal inheritance of social capital is an additional channel by which educational immobility is fostered. In the literature many possible connections between parental education, parental social capital, individual education and individual social capital are described. Figure 3 shows the conceptual framework of the possible relationships.

In sum, three paths channel the effects of parental background on educational attainment. First, parental education can directly affect the child's outcome in education. Genetic predisposition is one example for this pathway. At the same time, parental decision-making about schooling can have an effect on the educational career of the child. Particularly, in Germany, 
three aspects reinforce the strong direct connection between parental and individual education. Decisions about the type of secondary schooling happen at an early age, they are very decisive for the future educational career, and they are mostly made by the parents, which are likely to rely on their own educational experience. Secondly, the education of the child can be influenced directly by parental social capital. Parental involvement, in parent-teacher association (PTA) or other social environments of the child, is very beneficial for educational success (Putnam 1995). It is reasonable to argue that parents with higher levels of social capital are more involved in the social life of their child. Lastly, an indirect connection between parental social capital and individual education can be made. In a first stage, parents with high levels of social capital raise children with a similarly pronounced awareness for social norms and social trust (Putnam 2015). Likewise, the parental network size is likely to be a role model for the next generation's social networks. In a second step, the 'nurtured' social capital helps the child to proceed in educational success by relying on trustworthy cooperation with others in extended social networks.

Based on the theoretical assumptions and the reviewed literature, the following two hypothesis are made.

Hypothesis 1 The transmission of social capital has an indirect but distinct positive effect on educational attainment of the child.

Parental social capital is closely related to individual social capital. Individual social capital, subsequently, has a positive impact on individual educational success. This link is still visible when controlling for parental socio-economic status (SES) and parental education. The 2SLS model, which is explained in the next section, helps to isolate the linkage between parental social capital, social capital and educational attainment.

Hypothesis 2 The direct effect of parental education on child education is smaller with the inclusion of social capital transmission.

A conventional parental-child-education framework that does not take into account social capital transmission should show a much stronger relationship between parental and individual education. Past contributions might have overlooked this distinction. In addition, it can still be assumed that direct effects from parental to individual education are visible, since there are direct connections between the two measures that are unaffected by social capital transmission. The two hypotheses are tested with the use of the GSOEP household panel dataset under the application of descriptive statistics and a 2SLS Ordered Logit regression model.

When assessing the hypothesized relationship between the intergenerational transmission of social capital and the educational success of the child, the timing of the respective measurements is important. One would ideally measures the educational attainment of the child and the social capital of both parents and child at several points in time since the level of social capital of both generations is mutable during the educational career of the child. Unfortunately, the structure of the GSOEP survey only allows to take an ex-post perspective that does not allow an explicit analysis of the transmissions that take place during the earlier life course of the child. 


\section{Method and Data}

\subsection{GSOEP}

The German Socio-Economic Panel (GSOEP), which is the largest and most comprehensive household panel study of the German post-war society, serves as the underlying dataset for the presented analysis. It monitors about 12,000 households and more than 20,000 adult persons every year since 1984 . The survey includes topics about household composition, employment, income, education, family constellations, and values. The GSOEP makes is possible to include educational attainment, socio-economic status (SES), personal characteristics and social values of both the child and the parents into the analysis. Several additional samples have been assembled from East Germany and immigrants. Statements of parental educational attainment allow reconstructions of intergenerational trajectories of education. The panel structure of the survey allows following both individuals as well as age groups over time. Comparisons between generations can be made since for some personal characteristics and values both the parents and their children are interviewed. ${ }^{3}$ Given the design of the GSOEP survey, the educational attainment and social capital of each respondent is measured only at one point in time. Individuals between the age of 25 and 35 are considered to assure that their formal education is completed. ${ }^{4}$ In light of the considerations at the end of Sect. 2.4, it shall be underlined that this definition of educational attainment does not necessarily consider aspects of lifelong learning. A summary of the data used for the inferential part of the analysis can be found in Table 3 .

\subsection{How to Measure Education}

For a consistent empirical examination of educational mobility, adequate numerical measurements of education are decisive. Given the hierarchical structure of the German school system, the importance of vocational certificates for social success in Germany, and the distribution of educational attainment in the GSOEP, the following four categories of educational levels have are applied for both individuals and their parents. The first group [1] contains all individuals, who have achieved less than a higher secondary education. The second group [2] includes all individuals with a higher secondary education, including the Abitur or equivalent entry certificates to tertiary education. In the third group [3] all individuals with a higher secondary education and a vocational training are contained. Lastly, the fourth group [4] covers all individuals, who have completed any kind of tertiary education.

To capture the parental educational background, the highest education of among the parents has been selected as an indicator of parental education for descriptive statistics. The inferential model uses both the mother's and the father's level of educational attainment. Table 4 depicts the correlation of individual and parental education for the examined sample. This first empirical insight suggests that the individual level of education is most strongly related to the father's level of education, which is predominantly the highest level of attainment in the parental couple.

\footnotetext{
${ }^{3}$ Model specifications and the limited availability of controls reduce the final sample size of the inferential part of the analysis to 4148 .

4 The summary statistics in Table 3 indicate that the age distribution is centred around the age of 29 .
} 
Table 3 Summary of variables. Source: GSOEP 2003/2008/2013

\begin{tabular}{|c|c|c|c|c|}
\hline & Observations & $\begin{array}{l}\text { Average/per- } \\
\text { centage }\end{array}$ & Minimum & Maximum \\
\hline \multicolumn{5}{|l|}{ INDIVIDUAL } \\
\hline Age & 4148 & 29.31 & $25(28.72)$ & $35(31.15)^{\mathrm{a}}$ \\
\hline Male & 4148 & $50 \%$ & 0 & 1 \\
\hline [0-1] Migration background & 4148 & $3.9 \%$ & 0 & 1 \\
\hline [1-5] Health & 4148 & 3.94 & 1 & 5 \\
\hline [1-10] Number of close friends & 4148 & 4.88 & 0 & 10 \\
\hline [1-4] Generalised trust & 4148 & 2.67 & 1 & 4 \\
\hline [1-4] Trust in strangers & 4148 & 1.78 & 1 & 4 \\
\hline [1-5] Volunteer work & 4148 & 1.66 & 1 & 5 \\
\hline [1-5] Lend money & 4148 & 2.30 & 1 & 5 \\
\hline \multicolumn{5}{|l|}{ FATHER } \\
\hline [1-4] Education & 4148 & 2.87 & 1 & 4 \\
\hline Job: Employed full-time & 4148 & $74 \%$ & 0 & 1 \\
\hline Job: Employed part-time & 4148 & $2 \%$ & 0 & 1 \\
\hline Job: Other & 4148 & $2 \%$ & 0 & 1 \\
\hline Job: unemployed & 4148 & $22 \%$ & 0 & 1 \\
\hline [1-10] Number of close friends & 4148 & 4.05 & 0 & 10 \\
\hline [1-4] Generalised trust & 4148 & 2.64 & 1 & 4 \\
\hline [1-4] Trust in strangers & 4148 & 1.78 & 1 & 4 \\
\hline [1-5] Volunteer work & 4148 & 1.93 & 1 & 5 \\
\hline [1-5] Lend money & 4148 & 1.53 & 1 & 5 \\
\hline \multicolumn{5}{|l|}{ MOTHER } \\
\hline [1-4] Education & 4148 & 2.73 & 1 & 4 \\
\hline Job: Employed full-time & 4148 & $27 \%$ & 0 & 1 \\
\hline Job: Employed part-time & 4148 & $35 \%$ & 0 & 1 \\
\hline Job: Other & 4148 & $8 \%$ & 0 & 1 \\
\hline Job: Unemployed & 4148 & $30 \%$ & 0 & 1 \\
\hline Age of mother at birth & 4148 & 23.60 & 15 & 48 \\
\hline [1-10] Number of close friends & 4148 & 4.21 & 0 & 10 \\
\hline [1-4] Generalised trust & 4148 & 2.70 & 1 & 4 \\
\hline [1-4] Trust in strangers & 4148 & 1.75 & 1 & 4 \\
\hline [1-5] Volunteer work & 4148 & 1.71 & 1 & 5 \\
\hline [1-5] Lend money & 4148 & 1.52 & 1 & 5 \\
\hline
\end{tabular}

${ }^{\mathrm{a}}$ The 25 and $75 \%$ boundaries of the age distribution are shown in parenthesis 
Table 4 Parental education is strongly correlated to individual education. Source: GSOEP 2003/2008/2013

Own education $\quad$ Father's education $\begin{aligned} & \text { Mother's educa- } \\
& \text { tion }\end{aligned} \quad$\begin{tabular}{l}
$\begin{array}{l}\text { Highest } \\
\text { education }\end{array}$ \\
\hline
\end{tabular}

\begin{tabular}{llllll}
\hline Own education & 1 & & & \\
Father's education & 0.91 & 1 & & \\
Mother's education & 0.54 & 0.56 & 1 & 1 \\
Highest education & 0.82 & 0.88 & 0.77 & 1 \\
\hline
\end{tabular}

\subsection{How to Measure Social Capital}

For the empirical analysis of social capital, several indicators have been considered in the past. Some of them are of reoccurring prominence. Regarding previous reflections on the definition of social capital, three categories can be defined in the broadest sense: trust, cooperative norms, and networks. Given the limited amount of possible social capital factors available in the GSOEP, the following indicators have been selected in order to cover the three categories of trust, norms and networks. The aspect of trust is represented by two questions: "Trust in People in General" and "Cautions When Dealing With Strangers". Norms are represented by "Engagement in Volunteer Work" and "Lending Money to Friends". Networks are described by the "Number of Close Friends". 5

The support of social networks allows individuals to pursue their academic goals with the help of others. Social pressure but also difficulties in concrete tasks-school exams, for example - can more easily be mastered for children with an extended circle of supporters. Cooperative norms and most of all trust in others build the basis for social capital. The learning of these values and norms is the first step in teamwork, cooperative problem solving, and helps to ease orientation in social structures and hierarchies. Here, the perpetual nature of social capital unfolds. Once social networks are opened and spread, the positive resonance from social interaction further facilitates trust and willingness to cooperate. While the number of close friends directly measures the size of a social network, trust and cooperative can only be approximated by questions about trust in general, engagement in volunteering or lending money. In particular, the attidute towards lending money is expected to reflect the level of social capital in several ways. For one, lending money to someone is a strong cooperative statement, which requires a certain level of trust. At the same time, the question of lending money only becomes relevant in a social network of a sufficient size and activity.

\footnotetext{
5 The original wording of the respective questions and possible answers is the following. [TRUST]: "Please say to what extent do you agree to the following statement: In general, you can trust people."- "disagree strongly" [1], "disagree somewhat" [2], "agree somewhat" [3], "agree strongly" [4]. [STRANGER]: "Please say to what extent do you agree to the following statement: When dealing with strangers, it's better to be cautious before trusting them."- "disagree strongly" [1], "disagree somewhat" [2], "agree somewhat" [3], "agree strongly" [4]. [VOLUNTEER]: "Have you been engaged in voluntary work?"- "never" [1], "seldom" [2], "at least once a month" [3], "at least once a week" [4], or "daily" [5]. [MONEY]: "How often do you lend money to friends?"- "never" [1], "infrequently" [2], "sometimes" [3], "often" [4], or "very often" [5]. [FRIENDS]: "How many close friends do you have?"- "1" [1], "2" [2], "3" [3], "4" [4], "5" [5], "6" [6], "7" [7], "8" [8], "9" [9], "10 (and more)" [10].
} 
Fig. 4 Parental social capital jointly determines individual education and social capital. Source: GSOEP 2015 and own calculations

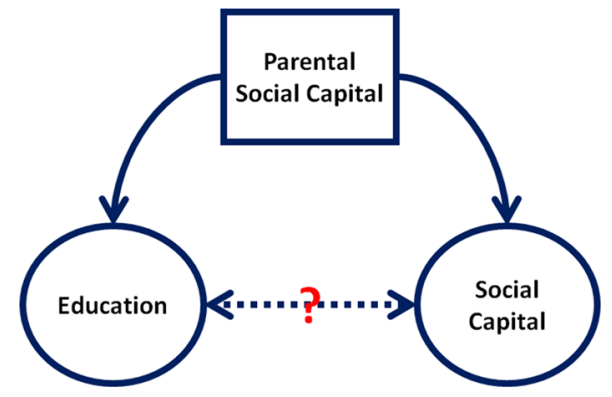

Since the design of the GSOEP does not allow a continuous measurement of social capital over time, characteristics of the child are measured after the completion of the educational career. This set-up relies on the assumption that social capital characteristics did not change significantly after adolescence. Certainly, a time series analysis of social capital characteristics, like generalized trust, would be desirable. However, the current literature regarding the life course dynamics of social capital suggests a certain stability of trust over time. Studies by Stolle and Hooghe (2004) and Claibourn and Martin (2000) reveal a fairly strong stability of trust over a 17-year period from 1965 to 1982 for a sample from the Youth-Parent Socialization Panel study of high school seniors and their parents in the United States in 1965. Similarly, Sønderskov and Dinesen (2014) find a strong correlation of trust over time, after the completion of adolescence for a Danish panel from 1990 to 2008. These results are again confirmed by Bekkers (2012) for the waves 2002, 2004, and 2006. Hence, the limitation of measuring social capital only once after the completion of the educational career, should not be regarded as a jeopardy for the overall analysis of this work.

\subsection{Instrumental Variable Approach}

The central concepts of this analysis, education, social capital, and parental social capital are intertwined in various ways. For example, it can easily be imagined that parental social capital influences both educational attainment and individual levels of social capital. At the same time, the reflections about education and social capital point to the mututal dependence between the two concepts. While social capital fosters educational success, as argued in this work, it could be that higher levels of education lead to an enhanced level of social capital. A stylised image of the relationships is given by Fig. 4.

The potential joint-determination of social capital and education as well as the mutual dependence between the two concepts circumvent an accurate estimation of coefficients. The results of any inferential model, which tries to directly explain educational attainment with social capital and parental social capital, can be jeopardized by endogeneity ${ }^{6}$ (Antonakis et al. 2014).

\footnotetext{
${ }^{6}$ On the one hand, the model is undermined by multicollinearity, since two of the independent variables

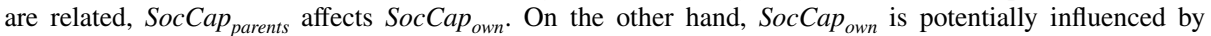
$E d u_{\text {own }}$, while the structure of the model assumes the opposite. Therefore, the error term $\epsilon$ is not independent of at least one of the exogenous variables and the assumption $\operatorname{Cov}(X, \epsilon)=0$ is violated.
} 
Fig. 5 The 2SLS captures the 'indirect' effect of parental social capital on education. Source: GSOEP 2015 and own calculations

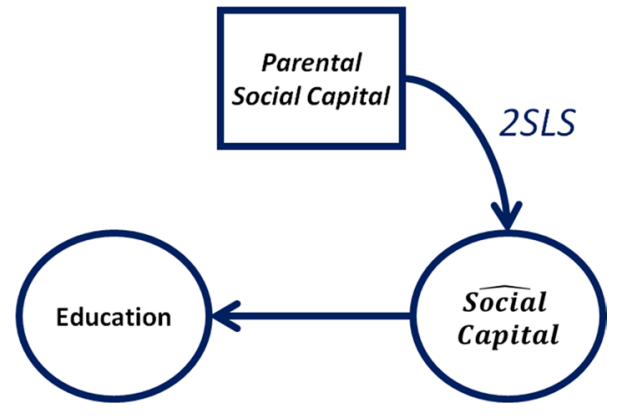

In order to overcome the problematic issues of multicollinearity and mutual dependence, a two-stage least-squares (2SLS) regression analysis is carried out. In a first step, a level of social capital is estimated with the use of other explanatory variables. The parental level of social capital (SocCap parents ) is used as an instrument in estimating SocCap own. The predicted values $\left(\widehat{\operatorname{SocCa}}{ }_{\text {own }}\right)$ can be used in order to estimate the level of $E d u_{\text {own }}$ without any distortion of the error term. A consistent estimation is possible since SocCap ${ }_{\text {own }}$ is determined by SocCap ${ }_{\text {parents }}$, which can not be influenced by $E d u_{\text {own }}{ }^{7}$ Since SocCap ${ }_{\text {own }}$ likewise depends on $E d u_{\text {parents, }}$, it can be argued that any additional relation between individual and parental education is not transmitted via social capital. Figure 5 illustrates the procedure:

In order to be considered as a suitable instrument SocCap parents needs to fulfill the following three conditions (Antonakis et al. 2014). First, the instrument needs to be valid,

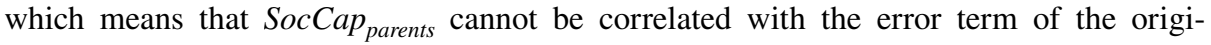
nal explanatory equation -in other words it must not suffer from the same problem as SocCap ${ }_{\text {own }} .{ }^{8}$ Secondly, the instrument must not have any explanatory power in the original equation, which means the only way in which $S o c C a p_{\text {parents }}$ can effect $E d u_{\text {own }}$ is via SocCap own $_{\text {. Lastly, the instrument should not be weak, which means that SocCap parents }}$ must be correlated with the endogenous explanatory variable(s), e.g., SocCap ${ }_{\text {own }}$.

In order to test for the adequacy of the 2SLS approach and the validity of the instrument applied, three different test statistics are consulted. The first test statistic is the WuHausmann test for exogeneity of the explanatory variables. The null hypothesis of the test assumes that the explanatory variables in the original, un-instrumented model, are exogenous. In this case it would not have been necessary to conduct a 2SLS approach. The second statistic is the F-Statistic for the power of the instruments. The null hypothesis of the test assumes that the instruments applied are not correlated strongly enough with the explanatory variables and that the instrument would be weak. Lastly, the Sargan test examines the model for over-identification. Its null hypothesis assumes that the instrument are valid.

\footnotetext{
7 Similarly, one could argue that the child's education in return influences parental social capital, since the environment of a new school might introduce new social networks to the parents. In order to circumvent this additional complication, the parental social capital of earlier survey periods is considered. Accordingly, the model results (see model line (3) in Table 5, for example) show no correlation between educational attainment and paternal generalised trust.
}

8 The assumption $\operatorname{Cov}\left(\operatorname{Soc} \operatorname{Cap}_{\text {parents }}, \epsilon\right)=0$ would need to hold. 


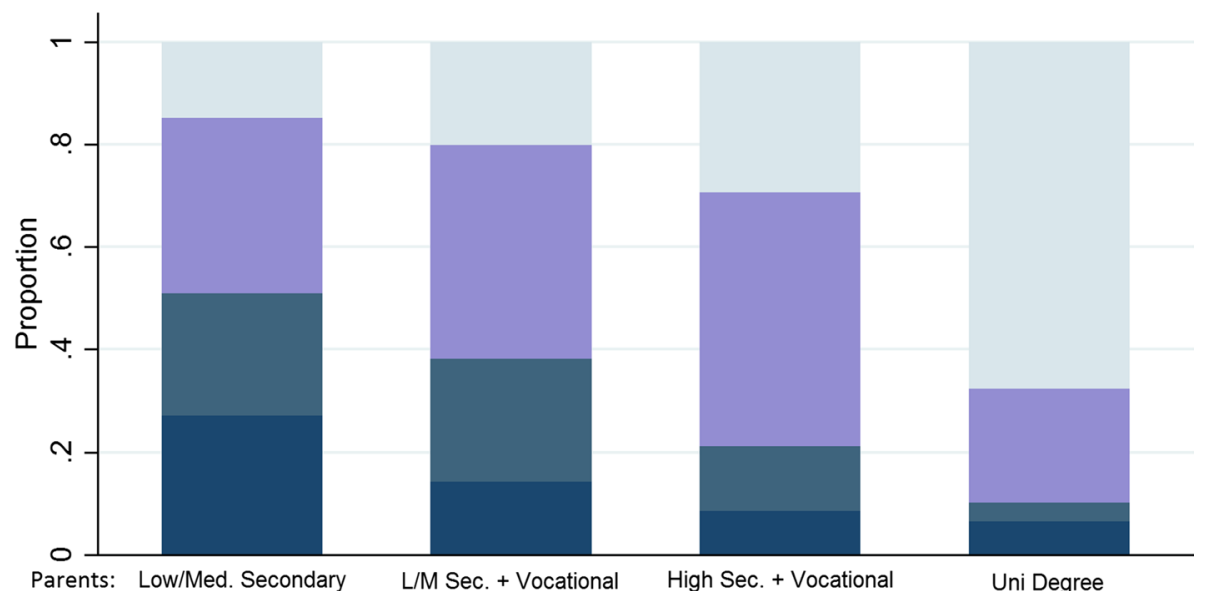

Child's Level of Education:

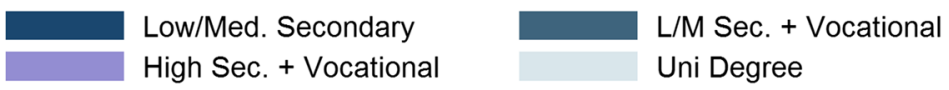

Education (25-35) by Parental Education Source: GSOEP 2012/13 \& own calculation

Fig. 6 The proportion of high educated children increases with parental education. Source: GSOEP 2015 and own calculations

\section{Results}

Three aspects present the results of this work; first, the current state of educational mobility in Germany is described. For the last two waves of the GSOEP, a clear relationship between parental and individual level of education is visible. The most pronounced gap in educational mobility appears in the odds of obtaining a university degree. Secondly, the longitudinal perspective of educational mobility in Germany is regarded. The development of educational mobility, parental education, and educational homogeneity of the household is considered. With the advancement of female education, household compositions have become more homogeneous over the last 30 years. For both women and men the proportion of individuals with tertiary education has risen significantly since the mid-eighties. At the same time, the educational mobility of the 25- to 35-year-old has been increasing steadily over the last 20 years. Lastly, the result section addresses the role of social capital transmission, which is assumed to be an unconventional determinant of educational immobility. Parental social capital can influence education via individual levels of social capital. The 2SLS model indicates that social capital factors, clearly shown for cooperative norms, are inherited form one generation to the other and ultimately determine educational attainment.

\subsection{The State of Educational Mobility}

In 2015, the OECD (2015) argued that Germany has the second lowest level of upward educational mobility among all member countries. This finding is retrieved in the presented analysis. Figure 6 depicts the educational attainment of the 25- to 35-year-old in 2012 and 


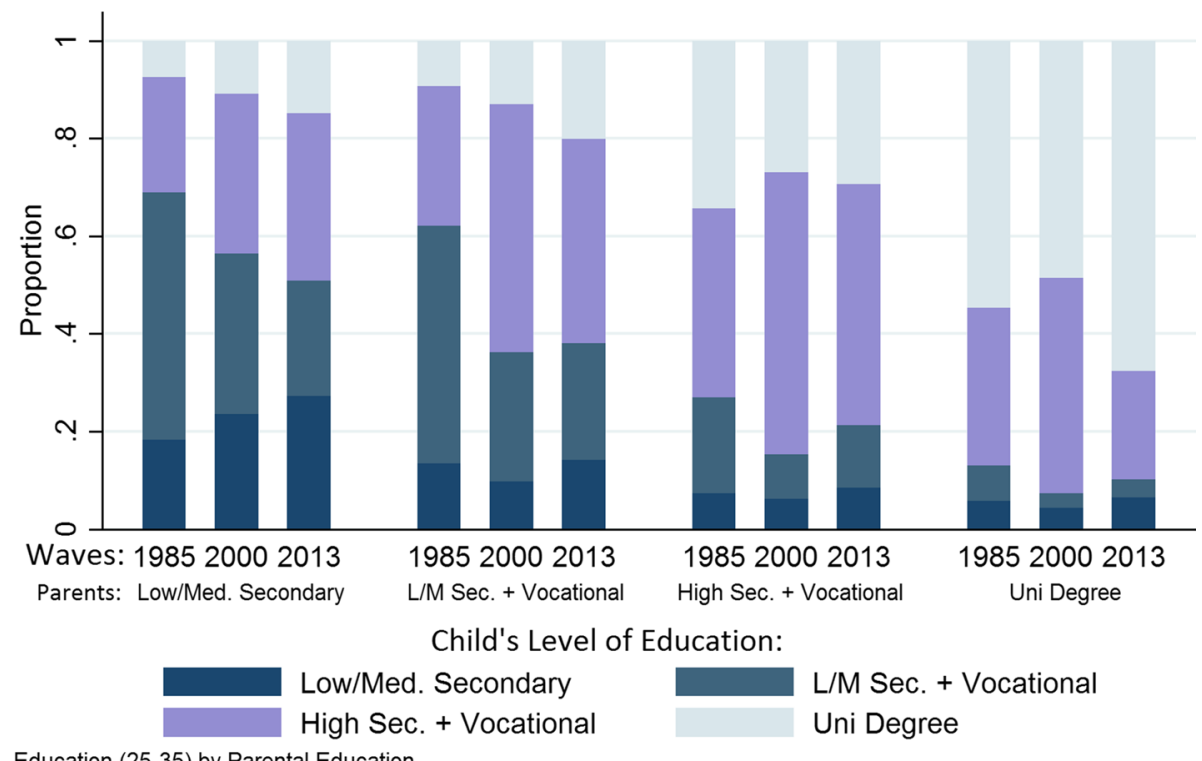

Education (25-35) by Parental Education Source: GSOEP \& own calculation

Fig. 7 The degree of educational moblitity has not changed much over the last three decades. Source: GSOEP 2015 and own calculations

2013 along the educational background of their parents. A clear pattern of dependence between parental and individual level of education is visible.

The share of young adults with low and medium secondary education gradually decreases with higher educational background of the parents. In the group with parents of low and medium secondary education, more than $50 \%$ have at maximum obtained a certificate of medium secondary education, including additional vocational training. In the last category - those with university-educated parents-only less than $10 \%$ have made this achievement. Parental education seems to be most trend setting for university degrees. Still, even in the second highest category individuals with a university degree only constitute $28 \%$. The share of university graduates is more than two times higher (68\%) for young adults with an academic family background. Nevertheless, some degree of educational mobility can be noticed. In all but the last group, individuals with a higher secondary education and vocational training constitute the largest share. This can be interpreted as an indication for the strong vocational training sector, which still warrants promising job opportunities in Germany alternative to a university education. For all young adults with non-academic family background, vocational training seems to be the forced alternative to a tertiary degree.

\subsection{Changes in Educational Mobility}

Educational mobility has changed over the last 30 years. Figure 7 extents the cross comparison of Fig. 6 to the previous three decades. In the comparison between 1985, 2000, and 2013, a shift of upward educational mobility can be noticed. For individuals from the lowest two educational groups, it has become more likely to obtain education above the level of parental education. At the same time, however, the distinction between academic and 


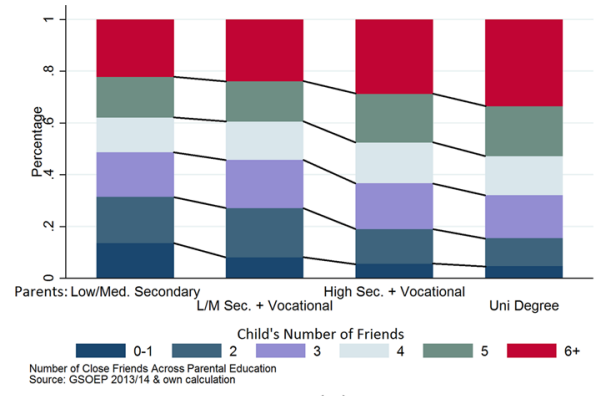

(a)

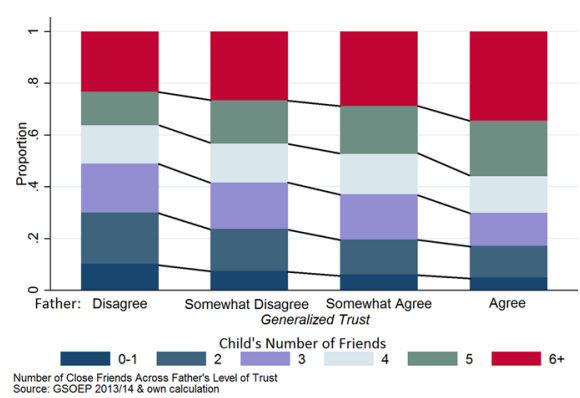

(b)

Fig. 8 a Parental education and b father's generalised trust are positively related with social network size. Source: GSOEP 2015 and own calculations

non-academic households has become more pronounced. While it is still relatively unlikely for children from low-educated families to attain university, the share of university graduates with at least one academic parent has increased significantly.

In the mid-nineties, the parental population of children with at least a higher secondary education was split in half between those with and without an Abitur, the certificate of higher secondary education. The composition has been gradually shifting towards a more highly educated parental population, since in 2013, almost four out of five children with higher education had parents of the same educational attainment. At the same time, educational inheritance has increased. As the correlation coefficient indicates, since the late nineties, individual education has become more dependent on the educational background of the parents. The results indicate that while the overall population for the young and the parental generation has become more educated on average, persistence in educational inheritance become more pronounced.

The design of the German school system favours the "academic track" as a mode for the completion of a university degree. Most students who want to graduate from polytechnics of universities need to finish the Gymnasium first. The steps of successfully obtaining the Abitur and completing university are therefore crucial benchmarks when examining educational mobility in Germany. Over the last decades, obtaining a university degree has become only slightly more likely for individuals with non-academic parents. While almost three out of four young adults with at least one university educated parent has obtained a university degree. At the same time the share of individuals with a higher secondary education and an additional vocational training has been growing in the lower three educational classes. In academic families today, this share is only half as large as it used to be 15 years ago. On the one hand, these observations indicate that children from academic families are over proportionally likely to enter the "academic track". On the other hand, the results underline the importance of a vocational career as an alternative to a university degree for individuals from non-academic families. This trend, previously described in the literature as a characteristic feature of the German educational system, seems to have consolidated in the last decades. 


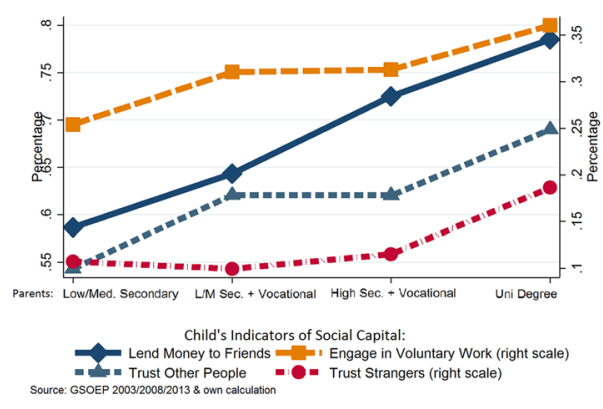

(a)

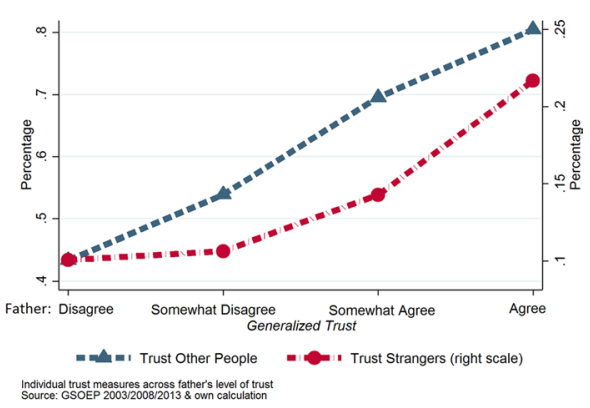

(b)

Fig. 9 a With higher parental education, and $\mathbf{b}$ higher levels of paternal generalised trust individual levels of social capital increase. Source: GSOEP 2015 and own calculations

\subsection{Social Capital Inheritance}

In the theoretical framework of social capital inheritance, it is assumed that social capital is unequally distributed among individuals in society according to the social background of their parents. Well-educated parents are socially more affluent and dispose of the resources and knowledge to foster their children's level of social capital. Children and young adults from households with a privileged level of social capital may seize their advantaged position and thrive with greater success in their educational career. Figures 8 and 9 relate the level of parental education (a) and parental social capital (b) to the proposed social capital indicators.

In Fig. 8 the network size of 25- to 35-year-old individuals in 2003, 2008, and 2013 $(\mathrm{N}=4148)$ is depicted by the number of close friends. On the left-hand side, the network size is shown by parental education (a), on the right hand side it is set in proportion to the level of generalised trust of the father. With regard to the size of social networks, a first tendency is visible. The higher the education level of the parents, the more likely the individual is to dispose of larger networks. The same is true for fathers with higher levels of social capital in terms of trust. Likewise, other social capital indicators can be associated with parental education and parental social capital. Figure 9 casts light on the relationship between the other social capital factors. On the left, the percentage of those who trust other people and strangers ([3] and [4]) and those who ever lent money to friends or ever engaged in volunteering ([2-5]) is shown along each group of parental education. On the right hand side, the percentage of those who trust other people and strangers ([3] and [4]) is graphed along the level of generalised trust of the father. The two other characteristics show only little variance along the paternal level of trust and are therefore not displayed.

In all cases of social capital indicators, a clear tendency is visible. The higher the parental education, the higher the social capital. Even though levels of trust in strangers and engagement in voluntary work are, on average, relatively low, rates increase by about $10 \%$ from the lowest to the highest educational class. This equals a doubling of the trust rates in strangers from low to high-educated households. For the relationship of trust between generations, the tendency is even more pronounced. Children's level of trust in general and in strangers doubles from the lowest to the highest category of paternal generalised trust. The two figures indicate two things: parental educational background and parental social capital closely coincide. At the same time, levels of parental social capital seems to be 


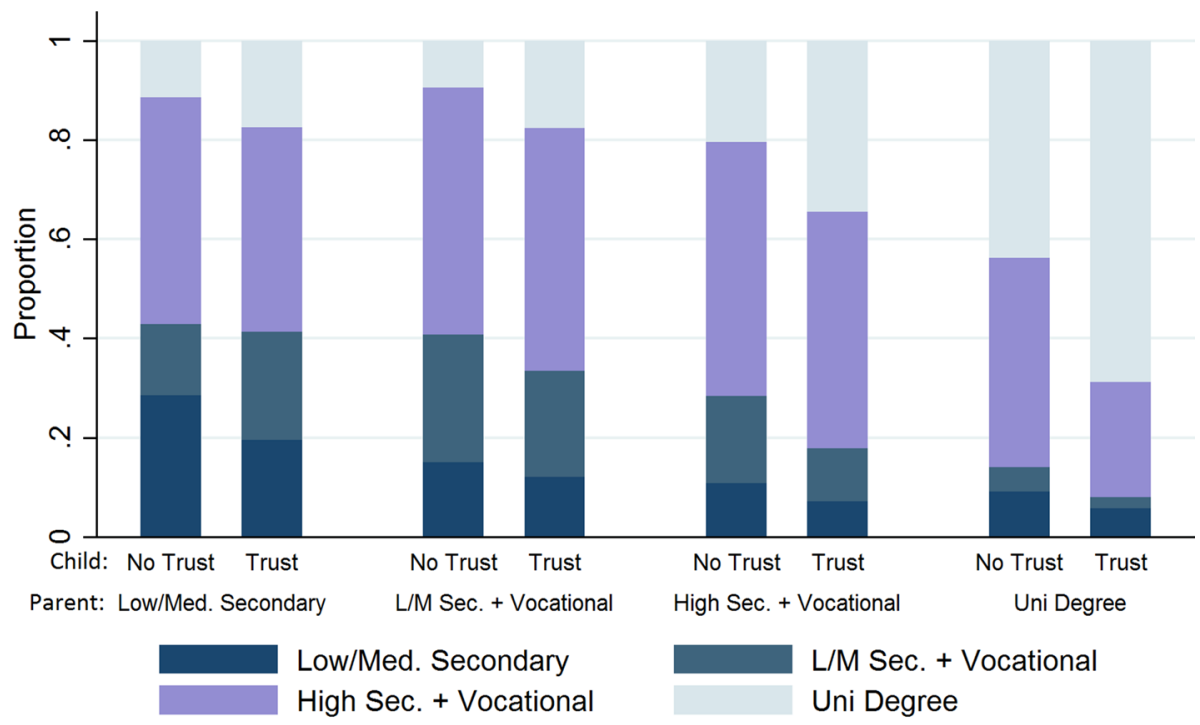

Education (25-35) by Social Capital and Parental Education Source: GSOEP 2012/13 \& own calculation

Fig. 10 Effects of social capital on education are visible within groups of parental education. Source: GSOEP 2015 and own calculations

more strongly related to the child's social capital development. Cooperative norms, for the example of lending money, are strongly influenced by the normative mind-set of the parents. The following subsection shows how a large part of the apparent link between parental education and social capital indicators is due to social capital transmission.

\subsection{The Indirect Effect of Social Capital}

It is theorised that parents indirectly project their level of education onto their children via social capital transmission. The model assumes that social capital transmission contributes to educational success independent of direct effect of parental education. The differences in educational outcome for groups of different levels of social capital should be visible even within groups of the same parental education. Figure 10 shows the proportions of educational outcomes for individuals with and without generalised trust, ${ }^{9}$ within each group of parental education. The indirect effect of social capital becomes visible in all four groups of parental education background. For all four categories, the share of individuals with high levels of education is larger in the subgroups with social trust. This suggests that social capital, independent of the parental education, has a positive association with educational attainment.

In order to disentangle diverse explanations, an inferential model is performed. According to the availability of the essential variables, the waves 2003, 2008, and 2013 of the

\footnotetext{
9 The generalised trust variable in this case is coded in a binary fashion; all individuals who "disagree strongly" [1] or "disagree somewhat" [2] are grouped under "No Trust", all individuals, who "agree somewhat" [3] or "agree strongly" [4] are grouped under "Trust".
} 
Table 5 Educational attainment explained in ordered logit model and 2SLS for trust. Source: GSOEP 2003/2008/2013
(1)
(2)
(3)
(4)
(5)

EDUCATION EDUCATION EDUCATION TRUST (2SLS) EDU (2SLS)

\section{INDIVIDUAL}

Age

Gender: Male

(Ref. female)

[0-2] Migration background

(Recoded)

[1-5] Health

FATHER

[1-4] Education

(Recoded)

Job: Employed full-time

(Ref. unemployed)

Job: Employed part-time

Job: Other

[1-10] Number of close friends

[1-4] Generalised trust

[1-4] Trust in strangers

[1-5] Volunteer work

[1-5] Lend money

\section{MOTHER}

[1-4] Education

(Recoded)

Job: Employed full-time (Ref. unemployed)

Job: Employed part-time

Job: Other

Age of mother at birth

[1-10] Number of close friends

\begin{tabular}{|c|c|c|c|c|}
\hline$-0.028 * * *$ & $0.030 * *$ & $0.027 * *$ & $0.015^{*}$ & 0.002 \\
\hline$(0.006)$ & $(0.013)$ & $(0.013)$ & $(0.008)$ & $(0.002)$ \\
\hline-0.027 & 0.103 & 0.108 & -0.092 & 0.019 \\
\hline$(0.057)$ & $(0.101)$ & $(0.102)$ & $(0.063)$ & $(0.012)$ \\
\hline$-0.640 * * *$ & 0.147 & 0.118 & $-0.176^{*}$ & 0.018 \\
\hline$(0.118)$ & $(0.194)$ & $(0.193)$ & $(0.101)$ & $(0.022)$ \\
\hline $0.086^{* *} *$ & 0.015 & 0.010 & $0.362 * * *$ & $-0.016^{*}$ \\
\hline \multirow[t]{30}{*}{$(0.035)$} & $(0.062)$ & $(0.062)$ & $(0.039)$ & (0.009) \\
\hline & $4.941 * * *$ & $4.946^{* * *}$ & 0.025 & $0.882^{* * * *}$ \\
\hline & $(0.100)$ & $(0.101)$ & $(0.041)$ & $(0.008)$ \\
\hline & 0.231 & 0.218 & 0.067 & $0.035^{* *}$ \\
\hline & $(0.140)$ & $(0.140)$ & $(0.086)$ & $(0.016)$ \\
\hline & -0.004 & -0.073 & -0.145 & -0.030 \\
\hline & $(0.380)$ & $(0.384)$ & $(0.223)$ & $(0.042)$ \\
\hline & 0.393 & 0.400 & -0.043 & 0.054 \\
\hline & $(0.370)$ & $(0.371)$ & $(0.229)$ & $(0.043)$ \\
\hline & & -0.031 & -0.014 & (Instruments) \\
\hline & & $(0.021)$ & $(0.013)$ & \\
\hline & & 0.063 & $0.426^{* * * *}$ & (Instruments) \\
\hline & & $(0.086)$ & $(0.054)$ & \\
\hline & & 0.052 & -0.002 & (Instruments) \\
\hline & & $(0.077)$ & $(0.047)$ & \\
\hline & & $0.100 * *$ & 0.043 & (Instruments) \\
\hline & & $(0.045)$ & $(0.027)$ & \\
\hline & & 0.079 & 0.017 & (Instruments) \\
\hline & & $(0.081)$ & $(0.050)$ & \\
\hline & $0.357 * * *$ & $0.355 * * *$ & 0.002 & $0.054 * * *$ \\
\hline & $(0.064)$ & $(0.065)$ & $(0.040)$ & $(0.007)$ \\
\hline & -0.036 & -0.076 & -0.004 & -0.005 \\
\hline & $(0.145)$ & $(0.146)$ & $(0.090)$ & $(0.017)$ \\
\hline & -0.090 & -0.165 & -0.043 & -0.010 \\
\hline & $(0.135)$ & $(0.136)$ & $(0.085)$ & $(0.016)$ \\
\hline & -0.079 & -0.114 & -0.065 & -0.015 \\
\hline & (0.199) & $(0.200)$ & $(0.125)$ & $(0.024)$ \\
\hline & $0.031 * * *$ & $0.028 * * *$ & $0.013^{* *}$ & $0.003 * * *$ \\
\hline & $(0.011)$ & $(0.011)$ & $(0.007)$ & $(0.001)$ \\
\hline & & 0.016 & 0.011 & (Instruments) \\
\hline
\end{tabular}

(0.021)

(0.013) 
Table 5 (continued)
(1)
(2)
(3)
(4)
(5)

EDUCATION EDUCATION EDUCATION TRUST (2SLS) EDU (2SLS)

[1-4] Generalised trust

[1-4] Trust in strangers

[1-5] Volunteer work

[1-5] Lend money

INSTRUMENTED

$\widehat{\text { Trust }}$

\section{Observations}

Adjusted $R^{2}$

Wu-Hausman F-statistic

First stage F-statistic

Sargan $C h i^{2}$

$\begin{array}{lll}0.152 * & 0.432 * * * & \text { (Instruments) } \\ (0.089) & (0.056) & \\ -0.103 & 0.085 * & \text { (Instruments) } \\ (0.077) & (0.047) & \\ -0.017 & 0.065 * * & \text { (Instruments) } \\ (0.051) & (0.031) & \\ 0.160 * * & 0.029 & \text { (Instruments) } \\ (0.080) & (0.050) & \end{array}$

$0.118 * * *$

(0.041)

4148

0.837

$8.912 * * *$

$21.14 * * *$

$20.75^{* *}$

Standard errors in parentheses

$* * * p<0.01 ; * * p<0.05 ; * p<0.1$

GSOEP survey are overlapped. In an initial Ordered Logit Model, the individual educational attainment, in four categories, is regressed on personal characteristics, parental socio-economic background, parental education and parental social capital indicators from the previous survey wave. The specifications of the model and limited availability of controls reduces the final sample to 4148 individuals. Model lines (1)-(3) in Table 5 show the step-wise inclusion of explanatory variables. The list of variables selected for this model stems from the selection of most cited empirical papers using national panel data the last 15 years in order to explain educational mobility. A detailed description of the papers can be found in Tables 1 and 2 .

In model line (3) it can clearly be seen how parental education, most dominantly the education of the father, has a strong positive impact on individual attainment. At the same time, some other parental characteristics, like mothers age at birth, paternal volunteering, maternal generalised trust, and maternal money lending, show a positive influence on educational attainment. The initial idea of the model is to outline the importance of social capital transmission in educational inheritance. Extending model (3) with individual social capital characteristics would jeopardise a consistent estimation, since parental social capital is assumed endogenous to social capital and education. An instrumental variable approach in form of a 2SLS model is performed as illustrated in Fig. 5.

Model (4) estimates the individual level of generalised trust in a first step with the application of parental social capital indicators as instruments. Individual and parental levels of trust are linked; both the father's and mother's level of generalised trust strongly predict individual levels of confidence. At the same time, maternal social capital factors, like volunteering and trust in strangers, influence individual levels of trust, too. Interestingly, parental education, unlike in the previous model, does not show any statistically 


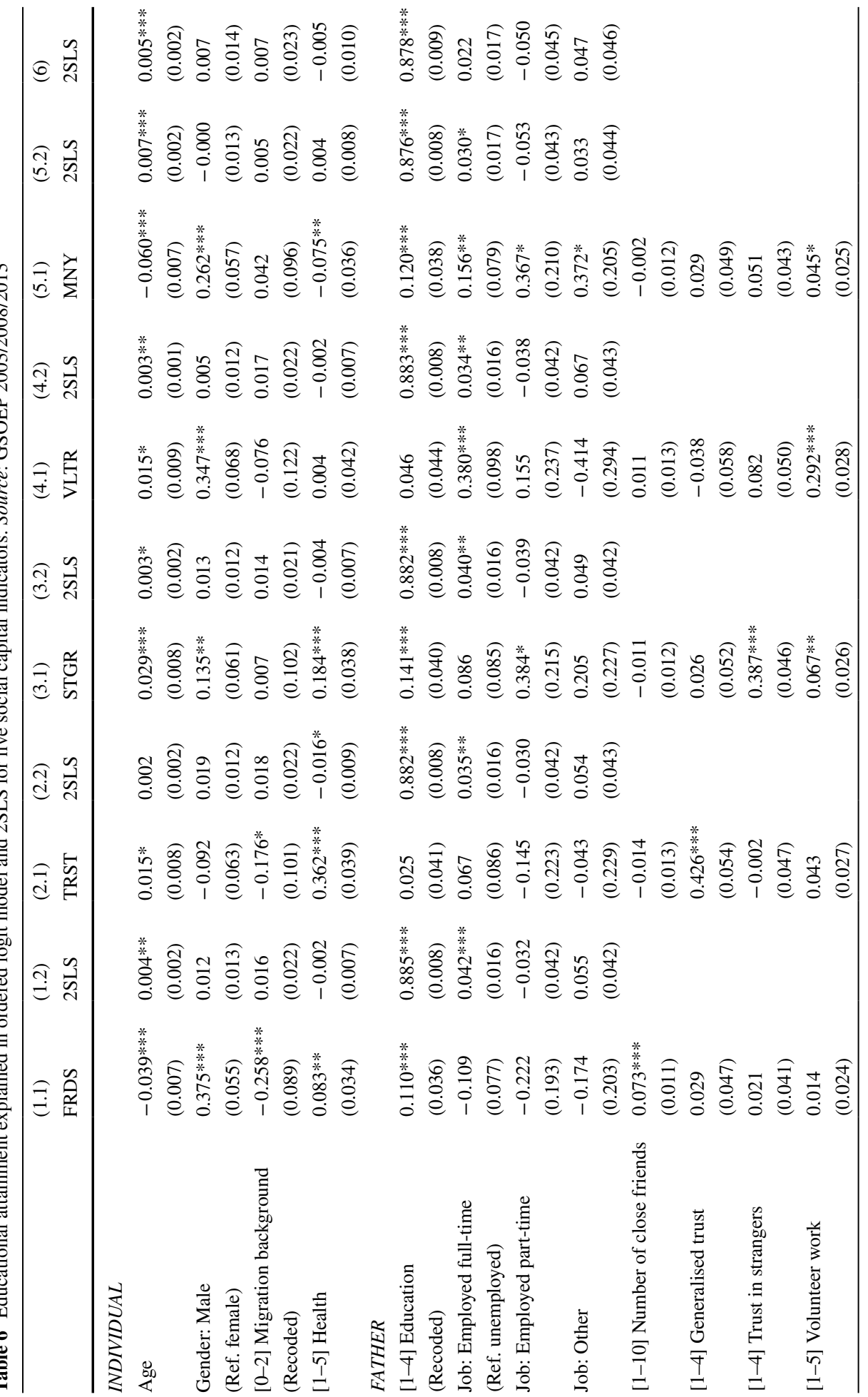




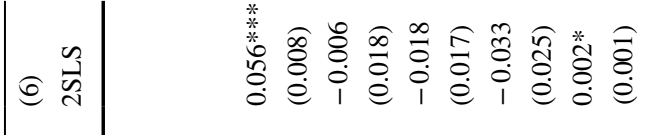

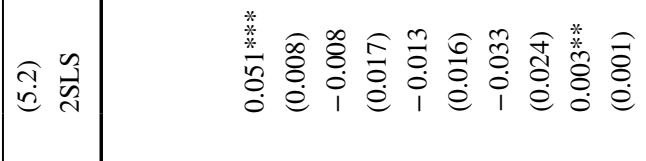

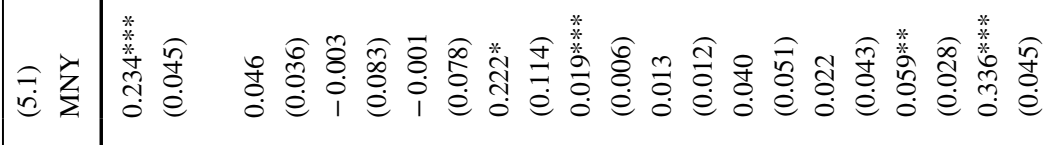

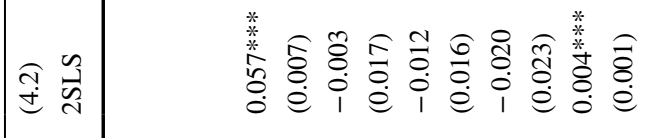

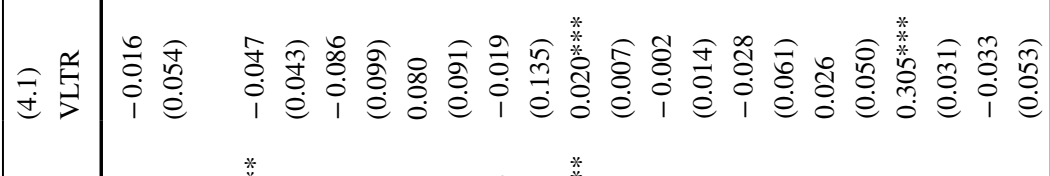

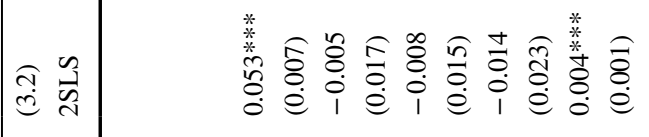

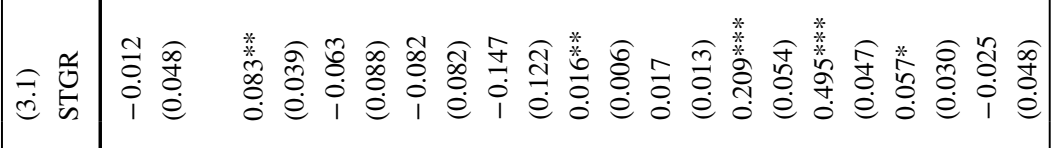

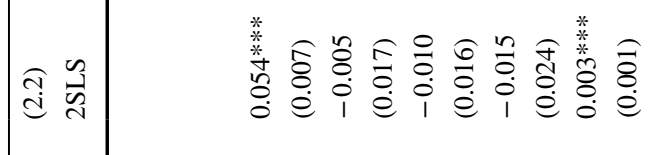

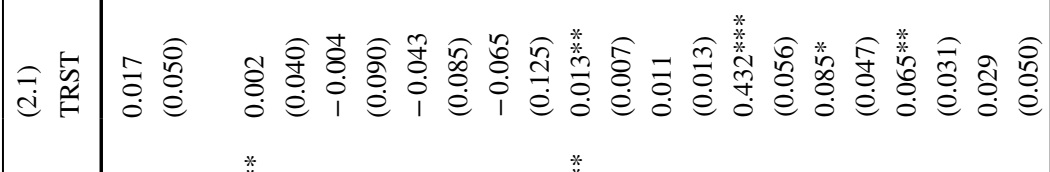

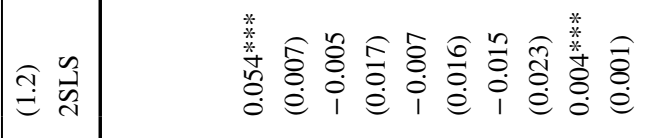

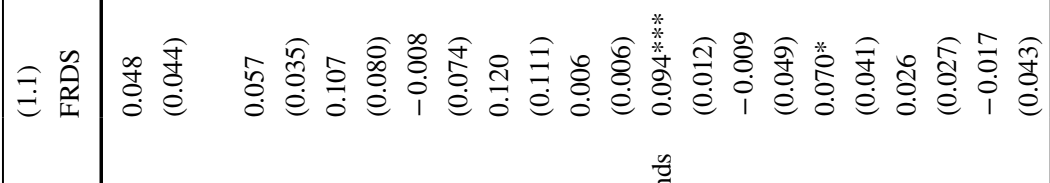

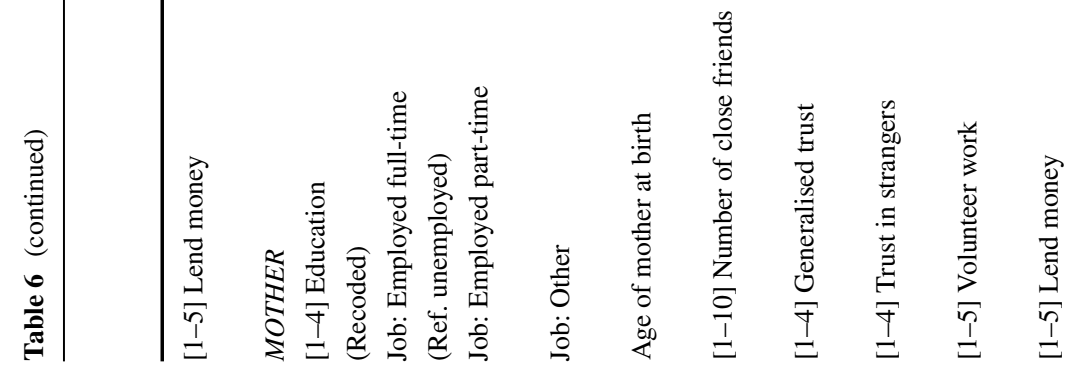




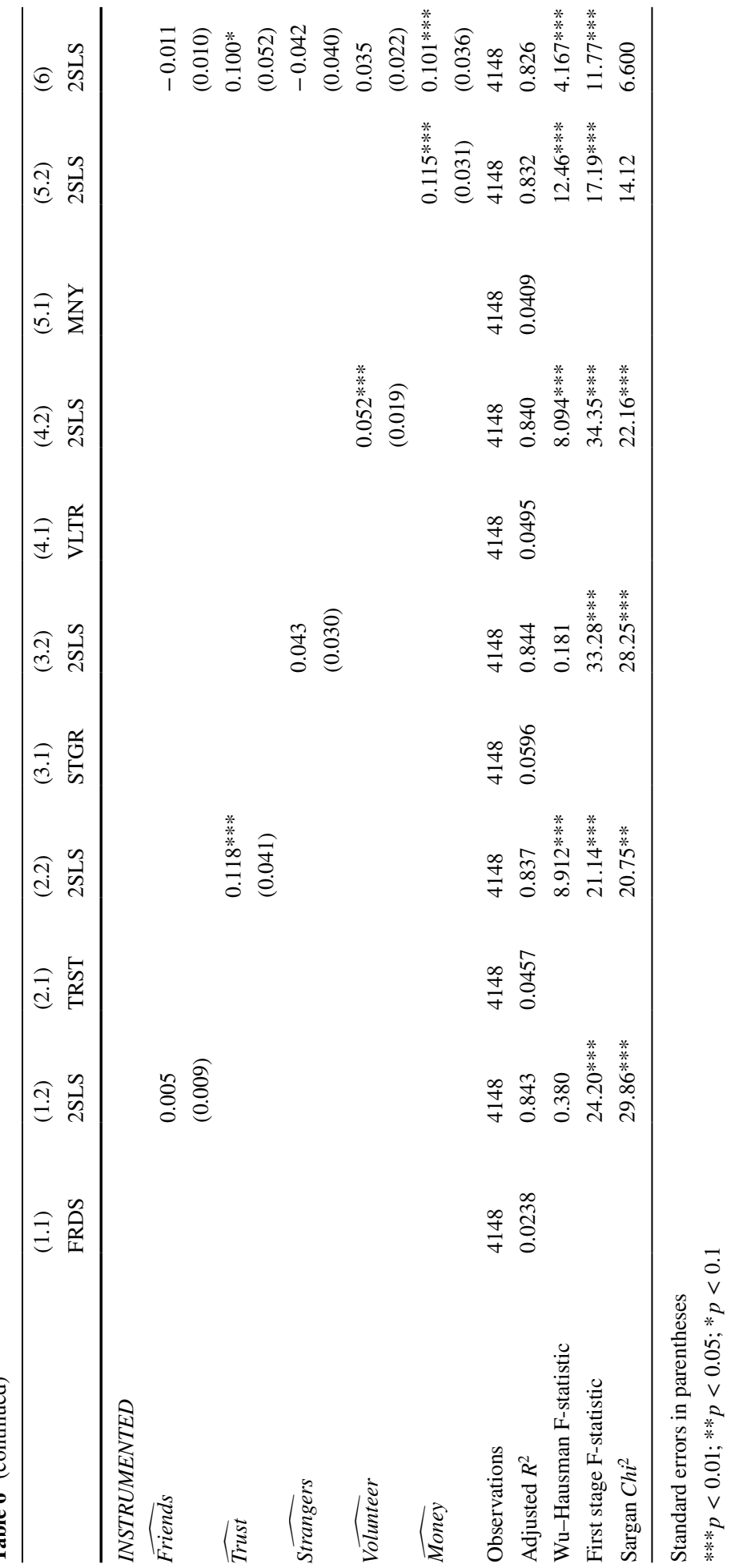


significant association with trust. The predicted values of generalised trust $(\widehat{\text { TRUST }})$ are then used to estimate the indirect effects of the parental background on individual educational attainment. In the final model (5), instrumented generalised trust shows a clear positive relation with educational attainment. This is a strong indication that parental social capital background influences education via social capital transmission. At the same time, parental education still exhibits positive effects on education, however, together with the instrumented social capital, effects of parental education are much smaller compared with model (3). Mother's age at birth, previous explanatory variables, remains to be significant, too. The instrumented model has a relatively stong explanatory power as suggested by the adjusted $R^{2}$. The Wu-Hausmann F-Statistic for endogeneity justifies the 2SLS approach, it suggests that an un-instrumented model would have suffered from endogeneity. The first stage F-Statistic indicates that the instruments are strongly correlated with the explanatory variable, the null hypothesis of weak instruments can therefore be rejected. However, the Sargan $C h i^{2}$ indicates that the model might suffer from over identification: the null hypothesis of valid instruments can not be maintained at $95 \%$ confidence.

Table 6 lists the results of the 2SLS model with the other social capital indicators. Number of friends, generalised trust, trust in strangers, volunteering, and lending money are instrumented by parental social capital in models (1-5). In model (6) all five social capital indicators are instrumented.

Number of friends and trust in strangers do not show any statistically significant effect on educational attainment. For both variables, the Wu-Hausmann test did not detect potential endogeneity. For trust in general, volunteering, and lending money potential endogeneity is indicated. All factors are significantly related to educational success, though only money lending appears to be predicted by valid and strong instruments, the null hypothesis of validity can not be rejected. Likewise, with the inclusion of all factors in model (6), statistics indicate valid and strong instruments. In the last two cases of the 2SLS approach lending money shows to capture much of the social capital inheritance, which influences educational attainment. This indication coincides with the observations made on a descriptive level earlier. The attitude towards lending money contains all three key elements of social capital. For one, lending money to someone is a strong cooperative statement, which requires a certain level of trust. At the same time, the question of lending money only becomes relevant in a social network of a sufficient size and activity.

In the model described above, factors of individual social capital are instrumented by parental levels of social capital. Some of the predicted values of individual social capital interfere with educational attainment. The results of the 2SLS model can be summarised in two main aspects. On the one hand, model test of endogeneity and validity underline that educational success is, to a sizable extent, explained by transmission of social capital. At the same time, we see that educational success is still influenced by family background via channels other than social capital transmission. Direct interference of parental decision-making during a child's educational career is reflected in this remaining explanatory portion.

Overall, the results confirm research hypothesis one: the transmission of social capital has an indirect but distinct positive effect on educational attainment. Even when considering individual and parental characteristics, as well as parental education, the 2SLS confirms a significant positive relationship between parental and individual social capital, while the predicted values of social capital are positively related to the child's education.

Research hypothesis two is likewise confirmed by the overall findings. The direct effect of parental education on child education is smaller under the consideration social 
capital transmission. This aspect of educational mobility has been overlooked in past contributions. Still, direct effects from parental to individual education are visible, it can be assumed that this finding reflects direct connections between the two measures, which are unaffected by social capital transmission such as parental decision making about early school entry.

The interpretation of the presented findings needs to consider the limitations of the selected cross-sectional approach. The structure of the GSOEP survey does not allow to track the development of social capital during the educational career. One can only observe the child's social capital at one particular stage, which is after the completion of the initial formal education. The results of this work help to explain the differences in educational status via differences in social capital at one given point in time. For future research ideas it would certainly be an interesting endeavour to explore the relationship between intergenerational social capital transmission and educational success in a time-series environment.

\section{Conclusion}

The prospects of future generations are formed by social mobility. In Germany, educational mobility is exceptionally low compared to other industrialised countries. Past contributions have explained these phenomena mainly with the early entry into secondary education and the promising prospects of the vocational training sector. However, these assertions seem incomplete in light of the increasing labour demand for university graduates and low rates of fluctuation between branches of secondary schools. It can be assumed that the social capital environment of the individual forms educational trajectories. Social capital, which is vital for educational success, is asymmetrically distributed among educational classes and unequally inherited to the next generation.

In comparison to previous studies (Hillmert and Jacob 2010), the educational success of Germany's most recently graduated cohort, the 25- to 35-year-old, still depends to a large extent to the educational achievements of the parent generation. Longitudinal investigations suggest that while the average level of education has been rising, mobility has even decreased over the last 30 years. The path to higher (tertiary) education in Germany, the "academic track", still leads through the completion of the Abitur and the subsequent entry into university. Both steps crucially depend on the educational career of the parents. Specifics of the German education system help to explain this observation. The decision about entry into higher secondary education is made at relatively early age, and is, in most cases, left with the parents. Still, while educational mobility seems not to have changed since the graduation of the "baby boomers", institutional changes and external factors should have facilitated intergenerational mobility. One possible explanation why this is not the case is the inheritance of social capital. Cooperative values and networks are important to educational success. They show persistence from one generation to the other and explain why mobility has not started to increase. Indeed, the size of social networks, trust in others, and cooperative norms, depend positively on the parental background. With parental social capital as an instrumental variable for individual social capital, inferential models how strong social capital is transmitted from one generation to the other and then leads to a higher educational attainment. A remaining direct effect of parental education on educational outcome can still be noticed.

The inheritance of social capital inequality can be explained by a class-specific exposure to surroundings of different social capital within and outside of the schooling environment. In 
their leisure time, children of educationally more affluent families might be exposed to social interactions that foster social capital more than the activities of children with less educated parents. At the same time, the perpetual nature of social capital acquisition leads to a similar effect in schools. Strong social capital norms and high levels of trust are more likely established in a strong social capital context. The more segregated schools become in terms of the social capital of their students, the less likely it will be for pupils to find a social environment, which fosters their social capital. With regard to this assumption, extensive all-day integrated comprehensive schooling and a later decision about entry into higher secondary education could potentially improve the degree of social capital inheritance and ease educational predetermination. The education system of Sweden could serve as an example at this point. In Sweden the decision about entry into higher secondary education is made at the age of 16 . Before this point in time, all pupils pass pre-school and a comprehensive compulsory school system. Here, apart from some merit-based separation, all pupils attend the same classes. The Swedish compulsory school-day typically lasts until the afternoon and includes school organised homework support and leisure activities. Overall, this creates a more holistic and less fragmented social capital environment, which authentically mimics the structure of society, reduces social capital disadvantages, and ultimately fosters educational and social mobility.

Acknowledgements Open access funding provided by Vienna University of Economics and Business (WU).

Open Access This article is distributed under the terms of the Creative Commons Attribution 4.0 International License (http://creativecommons.org/licenses/by/4.0/), which permits unrestricted use, distribution, and reproduction in any medium, provided you give appropriate credit to the original author(s) and the source, provide a link to the Creative Commons license, and indicate if changes were made.

\section{References}

Antonakis, J., Bendahan, S., Jacquart, P., \& Lalive, R. (2014). Causality and endogeneity: Problems and solutions. In D. V. Day (Ed.), The Oxford handbook of leadership and organizations (Vol. 1, pp. 93-117). New York: Oxford University Press.

Bekkers, R. (2012). Trust and volunteering: Selection or causation? Evidence from a 4 year panel study. Political Behavior, 34(2), 225-247.

Bourdieu, P. (1986). Forms of Capital. Westport: Greenwood Press.

Claibourn, M. P., \& Martin, P. S. (2000). Trusting and joining? An empirical test of the reciprocal nature of social capital. Political Behavior, 22(4), 267-291.

Coleman, J. S. (2000). Social capital in the creation of human capital. Amsterdam: Elsevier.

Davies, S., Maldonado, V., \& Zarifa, D. (2014). Effectively maintaining inequality in Toronto: Predicting student destinations in Ontario Universities. Canadian Review of Sociology/Revue canadienne de sociologie, 51(1), 22-53.

Fauser, M., Voigtländer, S., Tuncer, H., Liebau, E., Faist, T., \& Razum, O. (2012). Transnationality and social inequalities of migrants in Germany (Vol. 1, no. 11).

Ganzeboom, H. B., De Graaf, P. M., \& Treiman, D. J. (1992). A standard international socio-economic index of occupational status. Social Science Research, 21(1), 1-56.

Hagan, J., \& Foster, H. (2012). Intergenerational educational effects of mass imprisonment in America. Sociology of Education, 85(3), 259-286.

Hillmert, S., \& Jacob, M. (2010). Selections and social selectivity on the academic track: A life-course analysis of educational attainment in Germany. Research in Social Stratification and Mobility, 28(1), 59-76.

Íşler, O. (2015). The price of inequality: How today's divided society endangers our future. Review of Political Economy, 27(3), 475-479.

Jäger, M. M., \& Holm, A. (2007). Does parents' economic, cultural, and social capital explain the social class effect on educational attainment in the Scandinavian mobility regime? Social Science Research, 36(2), 719-744.

Knack, S., \& Keefer, P. (1997). Does social capital have an economic payoff? A cross-country investigation. The Quarterly Journal of Economics, 112(4), 1251-1288. 
Lepore, J. (2015). Richer and Poorer. The New Yorker. http://www.newyorker.com/magazine/2015/03/16/riche r-and-poorer. Accessed 6 June 2018.

Lin, N. (2000). Inequality in social capital. Contemporary Sociology, 29(6), 785-795.

Lowman, J., \& Elliott, M. (2010). A multilevel model of educational expectations of secondary school students in the United States. Social Psychology of Education, 13(1), 77-110.

Notten, N., \& Kraaykamp, G. (2010). Parental media socialization and educational attainment: Resource or disadvantage? Research in Social Stratification and Mobility, 28(4), 453-464.

OECD. (2015). Education at a Glance 2015. Education at a Glance. Paris: OECD Publishing.

Piketty, T. (2015). About capital in the twenty-first century. American Economic Review, 105(5), 48-53.

Putnam, R. D. (1995). Bowling alone: America's declining social capital. Journal of Democracy, 6(1), 65-78.

Putnam, R. D. (2015). Our kids: The American dream in crisis. New York: Simon and Schuster.

Putnam, R. D., Leonardi, R., \& Nanetti, R. Y. (1994). Making democracy work: Civic traditions in modern Italy. Princeton: Princeton University Press.

Roos, L. L., Hiebert, B., Manivong, P., Edgerton, J., Walld, R., MacWilliam, L., et al. (2013). What is most important: Social factors, health selection, and adolescent educational achievement. Social Indicators Research, 110(1), 385-414.

Sandefur, G. D., Meier, A. M., \& Campbell, M. E. (2006). Family resources, social capital, and college attendance. Social Science Research, 35(2), 525-553.

Sieben, I., Huinink, J., \& De Graaf, P. M. (2001). Family background and sibling resemblance in educational attainment. Trends in the former FRG, the former GDR, and the Netherlands. European Sociological Review, 17(4), 401-430.

Solow, R. M. (1995). But verify. The New Republic, 11, 36-39.

Sønderskov, K. M., \& Dinesen, P. T. (2014). Danish exceptionalism: Explaining the unique increase in social trust over the past 30 years. European Sociological Review, 30(6), 782-795.

Stadelmann-Steffen, I. (2011). Education policy and educational inequality-Evidence from the Swiss laboratory. European Sociological Review, 28(3), 379-393.

Stolle, D., \& Hooghe, M. (2004). The roots of social capital: Attitudinal and network mechanisms in the relation between youth and adult indicators of social capital. Acta Politica, 39(4), 422-441.

Tramonte, L., \& Willms, J. D. (2010). Cultural capital and its effects on education outcomes. Economics of Education Review, 29(2), 200-213.

Van Doorn, M., Pop, I., \& Wolbers, M. H. (2011). Intergenerational transmission of education across European countries and cohorts. European Societies, 13(1), 93-117.

Witte, K., \& Rogge, N. (2013). Dropout from secondary education: All's well that begins well. European Journal of Education, 48(1), 131-149. 